\title{
Simultaneous Determination of Ciprofloxacin Hydrochloride and Dexamethasone Sodium Phosphate in Eye Drops by HPLC
}

\author{
KATAKAM PRAKASH, KARANAM R. SIREESHA* \\ S.N. Vanita Pharmacy Mahavidyalaya, Exhibition grounds, Hyderabad- \\ 500001, Andhra Pradesh, India. \\ rupakr1@rediffmail.com
}

Received 11 September 2011; Accepted 8 November 2011

\begin{abstract}
A liquid chromatographic method was developed and validated for the simultaneous determination of ciprofloxacin hydrochloride and dexamethasone sodium phosphate in bulk and pharmaceutical formulations. Optimum separation was achieved in less than 5 min using a $\mathrm{C}_{18}$ column (250 $\mathrm{mmx} 4.6 \mathrm{~mm}$ i.d, $5 \mu$ particle size) by isocratic elution. The mobile phase consisting of a mixture of mixed phosphate buffer $(\mathrm{pH} 4)$ and acetonitrile $(65: 35, \mathrm{v} / \mathrm{v})$ was used. Column effluents were monitored at $254 \mathrm{~nm}$ at a flow rate of $1 \mathrm{ml} / \mathrm{min}$. Retention times of ciprofloxacin hydrochloride and dexamethasone sodium phosphate were 2.4 and 3.16 min respectively. The linearity of ciprofloxacin hydrochloride and dexamethasone sodium phosphate was in the range of 3-18 $\mu \mathrm{g} / \mathrm{ml}$ and 1-6 $\mu \mathrm{g} / \mathrm{ml}$ respectively. Developed method was economical in terms of the time taken and amount of solvent consumed for each analysis. The method was validated and successfully applied to the simultaneous determination of ciprofloxacin hydrochloride and dexamethasone sodium phosphate in bulk and pharmaceutical formulations.
\end{abstract}

Key words: Simultaneous determination, HPLC, Isocratic elution, Validation.

\section{Introduction}

Ciprofloxacin hydrochloride $(\mathrm{CFH})$ is a second generation fluoroquinolone, broad spectrum antibiotic used in bacterial infections ${ }^{1}$. It is chemically 1 - cyclopropyl- 6- fluoro- $1,4-$ dihydro- 4 oxo-7- (piperazin-1-yl) -3- quinoline carboxylic acid. Dexamethasone sodium phosphate (DSP) is a highly selective glucocorticoid which is widely used in ocular inflammatory diseases. Its chemical name is 9- fluoro-11b, 17, 21-trihydroxy-16 $\alpha$ methylpregna-1, 4- diene-3, 20-dione 21-(dihydrogen phosphate) disodium salt ${ }^{2}$. Dexamethasone in combination with ciprofloxacin hydrochloride is used in several antiinfective eye preparations to treat acute and sub acute conjunctivitis, keratitis and corneal ulcers caused by susceptible strains of the following aerobic gram positive and negative bacteria such as S. aureus, S. epidermidis, S. pneumonia and haemophilus influenza. 
In the literature, there are methods described for the individual estimation of fluoroquinolones and dexamethasone in aqueous samples and biological fluids by liquid chromatography ${ }^{3,4}$, liquid chromatography-fluorescence detection ${ }^{5}$. A few methods have also been described for the simultaneous determination of Dexamethasone with other drugs such as Chloremphenicol ${ }^{6}$, ofloxacin ${ }^{7,8,9}$. A gradient reverse phase HPLC method ${ }^{10}$ has been reported in the literature for simultaneous determination of CFH and DSP using a nucleosil C18 column with a mixture of mobile phase A consisted of 50 milli molar citric acid and potassium phosphate buffer. The mobile phase B consisted of $100 \% \mathrm{v} / \mathrm{v}$ acetonitrile, the flow rate $1.2 \mathrm{ml} / \mathrm{min}$, and the detection wavelength being $265 \mathrm{~nm}$. But no isocratic reverse phase HPLC method was reported, so an attempt was made to develop a simple, robust HPLC method for the estimation of these drugs available as eye drops.

The purpose of the present study was to develop a simple, sensitive and economical HPLC method for simultaneous determination of CFH and DSP in bulk and pharmaceutical formulations. The developed method has been validated ${ }^{11,12}$ by evaluation of the system suitability, specificity, linearity, limit of detection and quantification, precision, accuracy and recovery. The validated method was applied to the commercially available pharmaceutical formulations containing both the drugs.

\section{Experimental}

\section{Materials}

DSP and CFH were obtained as gift samples from Ajanta pharmaceuticals Ltd, Mumbai. HPLC grade acetonitrile was purchased from SD fine chemicals, India. Triple distilled water was used during the study. The pharmaceutical formulations containing $3 \mathrm{mg} / \mathrm{ml}$ of CFH and $1 \mathrm{mg} / \mathrm{ml}$ DSP (Zoxan-D eye drops, FDC pharmaceuticals Ltd, India.) was purchased from local market.

\section{Instrumentation}

A high performance liquid chromatograph (Shimadzu-10 AT VP) equipped with two pumps (Model-10AT VP) and Shimadzu UV-Visible detector (SPD-10AT VP), ultrasonic bath (Spincotech Pvt. Ltd, India).

\section{Chromatographic conditions}

For chromatographic analysis, a Chromosil C18 column $(250 \mathrm{mmx} 4.6 \mathrm{~mm}$ i.d, $5 \mu$ particle size) was used. Separation was carried out by isocratic elution. The mobile phase consisting of a mixture of mixed phosphate buffer $(\mathrm{pH} 4)$ and acetonitrile $(\mathrm{ACN})$ in the ratio of 65:35 $\mathrm{v} / \mathrm{v}$ was used. Mobile phase was filtered under vacuum from 0.45 membrane filter and degassed in ultrasonic bath for $30 \mathrm{~min}$ before passing through the instrument. The injection volume was $20 \mu \mathrm{l}$ and the flow rate was $1 \mathrm{ml} / \mathrm{min}$. UV detection was carried out at $254 \mathrm{~nm}$. Chromatographic separations were carried out at room temperature $\left(25-30^{\circ} \mathrm{C}\right)$.

\section{Preparation of solutions}

\section{Preparation of standard solution}

Stock standard solutions of CFH and DSP were prepared in the mobile phase at a concentration of $600 \mu \mathrm{g} / \mathrm{ml}$ and $200 \mu \mathrm{g} / \mathrm{ml}$. working standard solutions was prepared by serial dilution of stock solutions with the mobile phase. 


\section{Preparation of sample solution}

Sample solutions of CFH and DSP were prepared at a concentration of $600 \mu \mathrm{g} / \mathrm{ml}$ and $200 \mu \mathrm{g} / \mathrm{ml}$ by diluting $5 \mathrm{ml}$ of the ophthalmic solution to $25 \mathrm{ml}$ with the mobile phase. From this $0.25 \mathrm{ml}$ was taken and diluted to $10 \mathrm{ml}$ to get a concentration of $15 \mu \mathrm{g} / \mathrm{ml}$ and $5 \mu \mathrm{g} / \mathrm{ml}$ of CFH and DSP respectively.

\section{Method validation}

The developed analytical method was validated as per ICH and USP guidelines for the parameters like linearity, limit of detection (LOD), limit of quantification (LOQ), precision, specificity, accuracy, robustness, and system suitability.

\section{Linearity}

Six working standard solutions of each analyte in the concentration range of 3-18 $\mu \mathrm{g} / \mathrm{ml}$ for $\mathrm{CFH}$ and $1-6 \mu \mathrm{g} / \mathrm{ml}$ for DSP were prepared in triplicate and injected. Calibration curves were constructed by plotting concentration versus mean peak area.

\section{Limits of detection and Quantification}

According to ICH, limit of detection (LOD) is the lowest concentration of the analyte that can be detected and limit of quantification (LOQ) is the lowest concentration of analyte that can be detected with acceptable accuracy and precision. LOD and LOQ are calculated from the formulae $3.3 \sigma / \mathrm{s}$ and $10 \sigma / \mathrm{s}$ respectively. Where $\sigma$ is the standard deviation of $y$-intercepts of the regression line and $\mathrm{s}$ is the slope of the calibration curve.

\section{Precision}

The precision of the method was evaluated in terms of intermediate precision i.e., intra-day and inter-day precision and precision by different analysts. For intra-day precision three different concentrations of CFH and DSP in the linearity range was prepared in triplicate and was analyzed during the same day. For inter-day precision the same concentrations were analyzed on three consecutive days and RSD values were calculated. Instrument precision was analyzed by injection repeatability. This was examined by analyzing six injections of the mixture containing 15 and $5 \mu \mathrm{g} / \mathrm{ml}$ of $\mathrm{CFH}$ and DSP, respectively. RSD values were calculated from the peak areas and retention times of CFH and DSP.

\section{Accuracy}

Accuracy of the method was determined by recovery studies. These studies were carried out by addition of known amounts of CFH and DSP to a sample solution of known concentration and comparing calculated and measured concentrations. A sample solution containing CFH and DSP ( 0.6 and $0.2 \mathrm{mg} / \mathrm{ml}$, respectively) was prepared by diluting $5 \mathrm{ml}$ of the ophthalmic solution to $25 \mathrm{ml}$ in a volumetric flask, and make up the solution with the mobile phase. Samples $(0.1 \mathrm{ml})$ of the filtered solution were transferred to $10 \mathrm{ml}$ volumetric flasks containing $0.1,0.15$, and $0.2 \mathrm{ml}$ of CFH and DSP standard solution, and analyzed.

\section{Specificity}

Specificity of an analytical method may be defined as the ability of the method to measure accurately and specifically the analyte in presence of additional components such as matrix, impurities, degradation products and other related substances. The chief excipient present in the eye drops is benzalkonium chloride which is used as preservative. Sample solution 
containing benzalkonium chloride was injected into the system and chromatogram was recorded.

\section{Robustness}

Robustness of the method was evaluated by deliberately varying method parameters such as detection wavelength and flow rate. Detection wavelength was changed from $254 \mathrm{~nm}$ to $254 \pm 2 \mathrm{~nm}$ and flow rate was changed from $1 \mathrm{ml} / \mathrm{min}$ to $1 \pm 0.1 \mathrm{ml} / \mathrm{min}$. Effect of these changed parameters was studied by injecting the sample in to the system.

\section{System suitability}

System suitability was established in order to determine the adequate resolution and reproducibility of the proposed method. Suitability parameters including retention factor, resolution, asymmetry factor, plate number were investigated.

\section{Assay of the marketed formulation}

The developed method was applied to the simultaneous determination of CFH and DSP in pharmaceutical formulations. Sample was analyzed by performing six independent determinations and each series was injected in triplicate.

\section{Results and Discussion}

\section{Mobile phase optimization}

Chromatographic parameters were optimized to develop a HPLC method for simultaneous determination of CFH and DSP with short analysis time $(<10 \mathrm{~min})$, and acceptable resolution $\left(\mathrm{R}_{\mathrm{S}}>2\right)$. Various compositions of mobile phases like methanol: buffer and ACN: buffer in different ratios were tried. But with mixed phosphate buffer $(\mathrm{pH} 4)$ and $\mathrm{ACN}$ in the ratio of $65: 35$ at a flow rate of $1 \mathrm{ml} / \mathrm{min}$, symmetrical peaks with good resolution were obtained. The optimum wavelength for detection was set at $254 \mathrm{~nm}$ at which better detector response for both drugs was obtained. The retention times were 2.04 and $3.16 \mathrm{~min}$ for CFH and DSP respectively (fig. 2).

\section{Validation}

Calibration graphs were constructed by plotting the peak area versus their corresponding concentrations. Good linearity was obtained in the range of $3-18 \mu \mathrm{g} / \mathrm{ml}$ and $1-6 \mu \mathrm{g} / \mathrm{ml}$ for $\mathrm{CFH}$ and DSP. The results are shown in table 1. Limit of detection (LOD) and limit of quantification (LOQ) were calculated from the slope and standard deviation of y-intercepts of the regression line of the calibration curve. For CFH it was found to be 0.028 and 0.086 $\mu \mathrm{g} / \mathrm{ml}$ and for DSP 0.015 and $0.046 \mu \mathrm{g} / \mathrm{ml}$ respectively. The precision of the method and instrument precision was evaluated and relative standard deviation (RSD) values were calculated. The RSD values for CFH and DSP showed that the precision of the method was satisfactory. The results are shown in table 2 . The accuracy of the method was determined by recovery studies. The recoveries were close to $100 \%$ for CFH and DSP; the results are given in the Table 3. Developed method was found to be robust when the detection wavelength and flow rate was changed from $254 \mathrm{~nm}$ to $254 \pm 2 \mathrm{~nm}$ and $1 \mathrm{ml} / \mathrm{min}$ to $1 \pm 0.1 \mathrm{ml} / \mathrm{min}$. There was no considerable change in the peak areas and retention times. Using $0.9 \mathrm{ml} / \mathrm{min}$ flow rate, the retention time for CFH and DSP were found to be 2.39 and $3.42 \mathrm{~min}$ respectively and with $1.1 \mathrm{ml} / \mathrm{min}$ flow rate, retention times for CFH and DSP were found to be 1.92 and $3.01 \mathrm{~min}$, respectively without affecting the resolution of the drugs. 
Simultaneous Determination of Ciprofloxacin Hydrochloride and Dexamethasone 1081 Sodium Phosphate

When detection wavelength was changed to $254 \pm 2 \mathrm{~nm}$, the retention time for CFH and DSP were not changed from the normal. System suitability parameters are shown in table 4 .

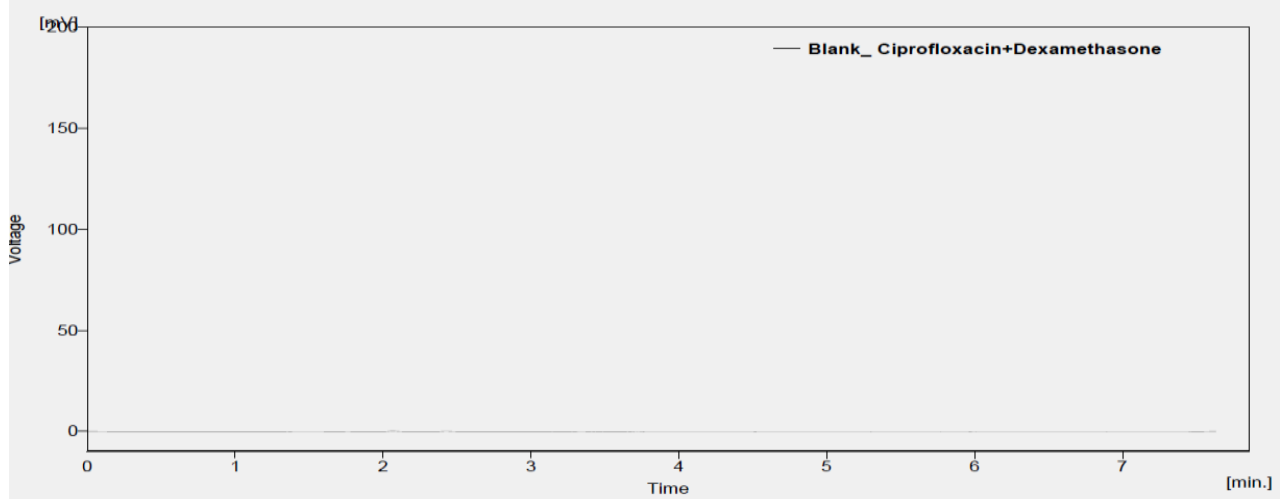

Figure 1: Chromatogram for blank.

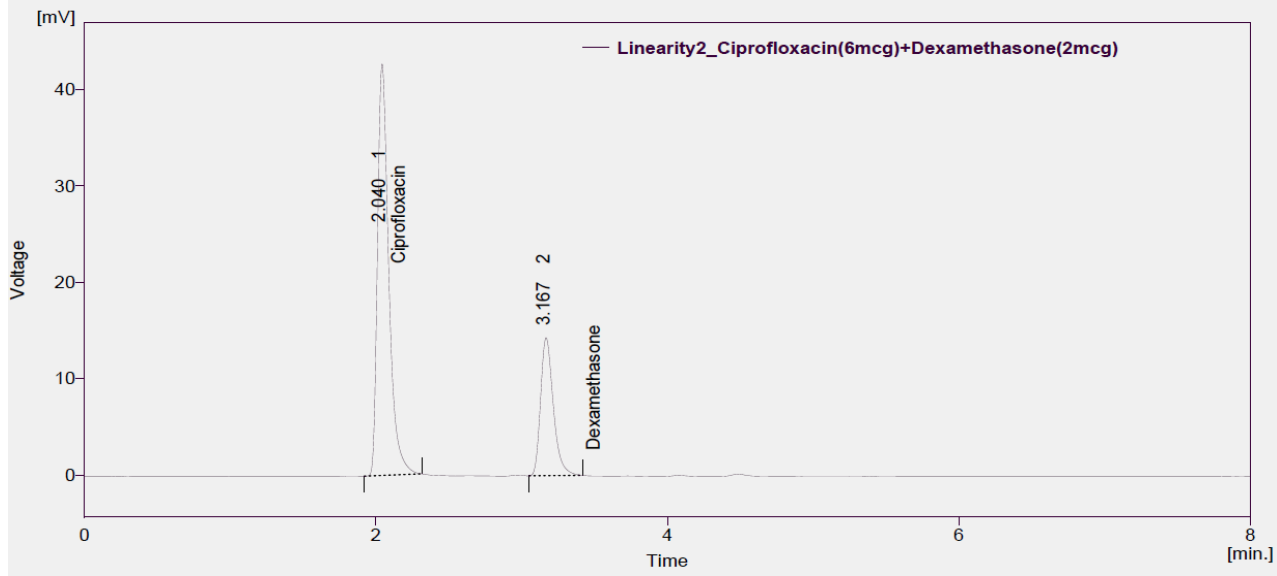

Figure 2: Typical chromatogram for the standard solution of CFH and DSP.

Table 1. Linearity by regression analysis $(n=6)$.

\begin{tabular}{|c|c|c|c|}
\hline Substance & $\mathrm{R}^{2}$ & Slope & Conc. range $(\mu \mathrm{g} / \mathrm{ml})$ \\
\hline CFH & 0.9986 & 36.23 & $3-18$ \\
\hline DSP & 0.999 & 41.37 & $1-6$ \\
\hline
\end{tabular}

' $\mathrm{n}$ ' is number of determinations. 
Table 2. Precision expressed as \%RSD.

\begin{tabular}{|c|c|c|}
\hline Parameters & CFH & DSP \\
\hline Intra-day precision & 0.24 & 0.52 \\
\hline Inter-day precision & 0.95 & 0.82 \\
\hline Analyst precision & 0.17 & 0.21 \\
\hline Injection repeatability for $t_{R}$ & 0.80 & 0.13 \\
\hline Injection repeatability for peak area & 0.88 & 1.03 \\
\hline
\end{tabular}

' $\mathrm{n}$ ' is number of determinations and RSD is relative standard deviation.

Table 3. Recovery studies ( $\mathrm{n}=6)$.

\begin{tabular}{|c|c|c|c|c|}
\hline Drug & $\begin{array}{c}\text { Concentration } \\
\mu \mathrm{g} / \mathrm{ml}\end{array}$ & $\begin{array}{c}\text { Amount recovered } \\
\mu \mathrm{g} / \mathrm{ml}\end{array}$ & \%recovery & $\% \mathrm{RSD}$ \\
\hline \multirow[t]{3}{*}{$\mathrm{CFH}$} & 12 & 11.93 & 99.38 & 0.7 \\
\hline & 15 & 15 & 99.97 & 0.50 \\
\hline & 18 & 17.73 & 98.52 & 0.37 \\
\hline \multirow[t]{3}{*}{ DSP } & 4 & 3.97 & 99.34 & 1.02 \\
\hline & 5 & 4.99 & 99.72 & 1.03 \\
\hline & 6 & 5.91 & 99.49 & 0.70 \\
\hline
\end{tabular}

' $\mathrm{n}$ ' is number of determinations and RSD is relative standard deviation.

Table 4. System suitability parameters $(n=6)$.

\begin{tabular}{|c|c|c|}
\hline Parameters & CFH & DSP \\
\hline Retention time $\left(\mathrm{t}_{\mathrm{R}}\right)$ & 2.04 & 3.16 \\
\hline Asymmetry factor & 1.6 & 1.5 \\
\hline Resolution & - & 7.36 \\
\hline Number of plates & 3343 & 6377 \\
\hline LOD $(\mu \mathrm{g} / \mathrm{ml})$ & 0.028 & 0.015 \\
\hline LOQ $(\mu \mathrm{g} / \mathrm{ml})$ & 0.086 & 0.046 \\
\hline
\end{tabular}

' $\mathrm{n}$ ' is number of determinations. 


\section{Assay of the marketed formulation}

According to $\mathrm{ICH}$ in the case of assay, demonstration of specificity requires that the procedure is unaffected by the presence of impurities or excipients. The assay value of the marketed formulation was found to be within the limits. The low RSD value indicated suitability of this method for routine analysis of CFH and DSP in pharmaceutical dosage forms. Chromatogram of the sample shows that there was no interference from the excipients present in the formulation (Fig. 3); this indicates the specificity of the method. The results are shown in table 5.

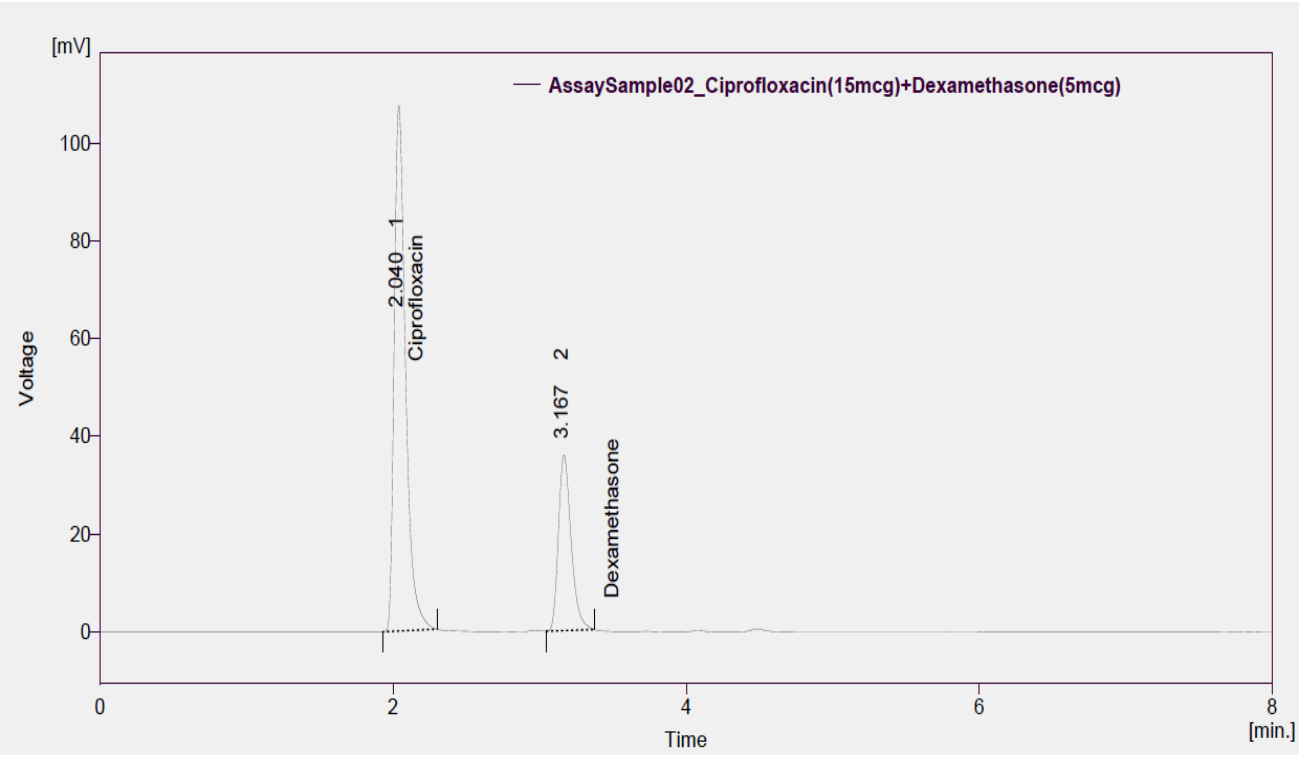

Figure 3: Typical chromatogram for the sample solution of CFH and DSP.

Table 5. Assay of eye drops $(n=6)$.

\begin{tabular}{|c|c|c|c|c|}
\hline Drug & Label claim & Amt found & Mean & \%RSD \\
& $\mathrm{mg} / \mathrm{ml}$ & $\mathrm{mg} / \mathrm{ml}$ & \%recovery & \\
\hline $\mathrm{CFH}$ & 3 & 2.99 & 99.83 & 0.15 \\
\hline DSP & 1 & 0.99 & 99.91 & 0.29 \\
\hline
\end{tabular}

Zoxan -D eye drops containing 3mg/ml CFH and $1 \mathrm{mg} / \mathrm{ml} \mathrm{DSP}$.

\section{Conclusion}

The method described in this paper for the simultaneous estimation of CFH and DSP was found to be simple, sensitive, accurate, precise, rapid, robust and economical. The analytical conditions and the solvent system developed provided good resolution within a short analysis time. The RSD for all parameters was found to be within the limits, which indicates 
the validity of method and assay results obtained by this method are in fair agreement. Thus the developed method can be proposed for routine analysis of CFH and DSP in laboratories and for quality control purposes.

\section{References}

1. Osman C, Cosar B, Yuksel T, Umit Y, Nursabah E B, Atilla B and Soguz K, Orhan Z, Eye., 1999, 13, 656-659.

2. Indian Pharmacopoeia, Published by The Indian Pharmacopoeia commission, Ghaziabad. 2007; Vol. 2, 1005-1007.

3. Chen Q, Zielinski D, Chen J, Koski A, werst D and Nowak S , J Pharm Biomed Anal., 2008, 48(3), 732-738.

4. Hyung WK and Donald JD, Korean J opthalmol., 1995, 9, 79-83.

5. Joana S, Gilberto A, Ana F, Angelina P, Celeste L and Amilcar F, Biomed chromatogr., 2011, 25, 535-41.

6. Iqbal MS, Shad MA, Ashraf MW, Bilal M and Saeed M. Chromatographia., 2006, 64, 219-222.

7. Tan R, Mo M and Li G, West China J Pharm Sci., 1999, 1, 20.

8. Tang Kai Z, Fu Xiu J and Li G, Chinese J Hospital Pharm., 2002, 1, 12.

9. Ali MS, Ghori M and Saeed A, J Chromatographic Sci., 2002, 40, 429-433.

10. Rele RV and Warkar CB, Asian J Res Chem., 2010, 3, 673.

11. United States Pharmacoepia 23, The United States pharmacoepial convention, twinbrook parkway, Rockville, MD. 1995; 1982-1984.

12. Validation of analytical procedures Q2 B. International conference on harmonization, IFPMA, Geneva. 2003. 


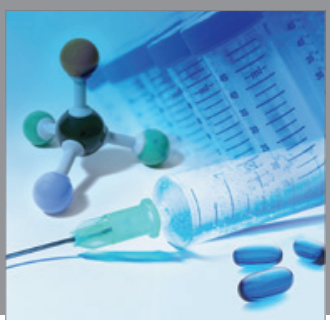

International Journal of

Medicinal Chemistry

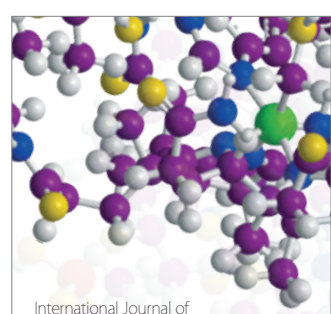

Carbohydrate Chemistry

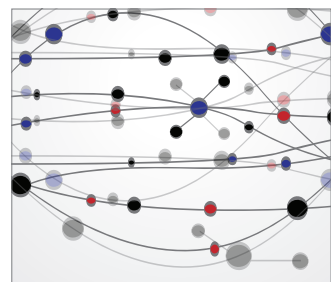

The Scientific World Journal
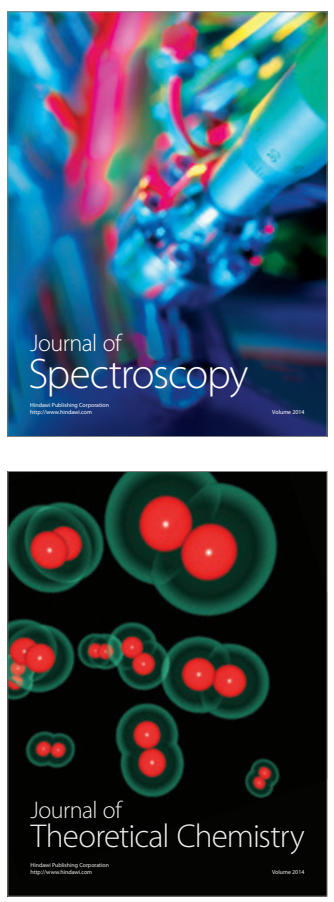
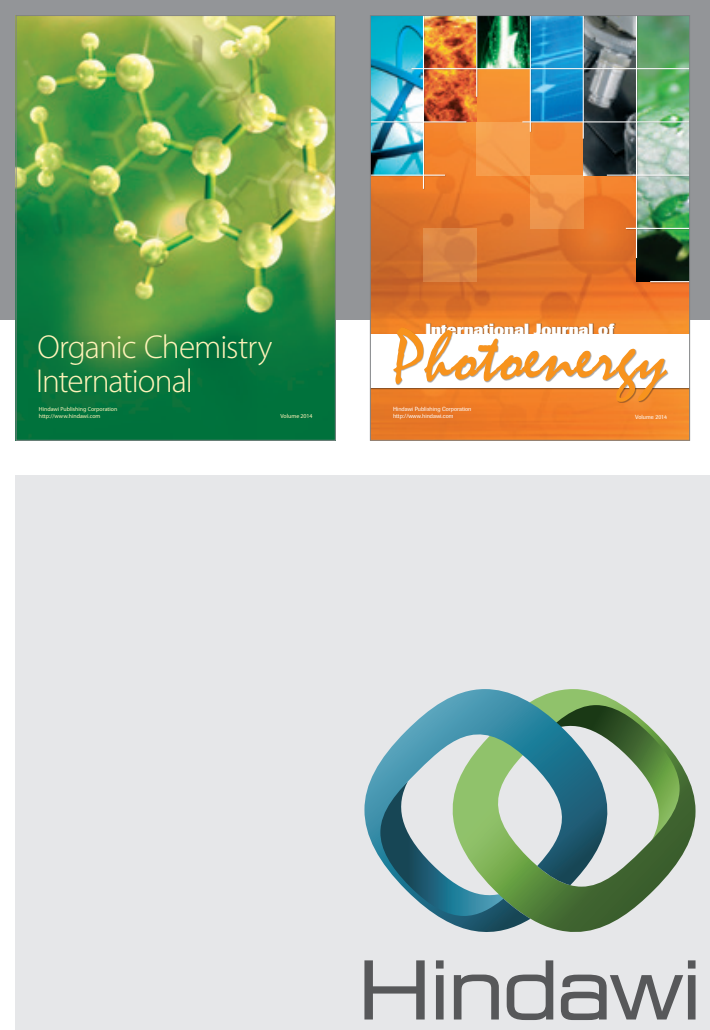

Submit your manuscripts at

http://www.hindawi.com
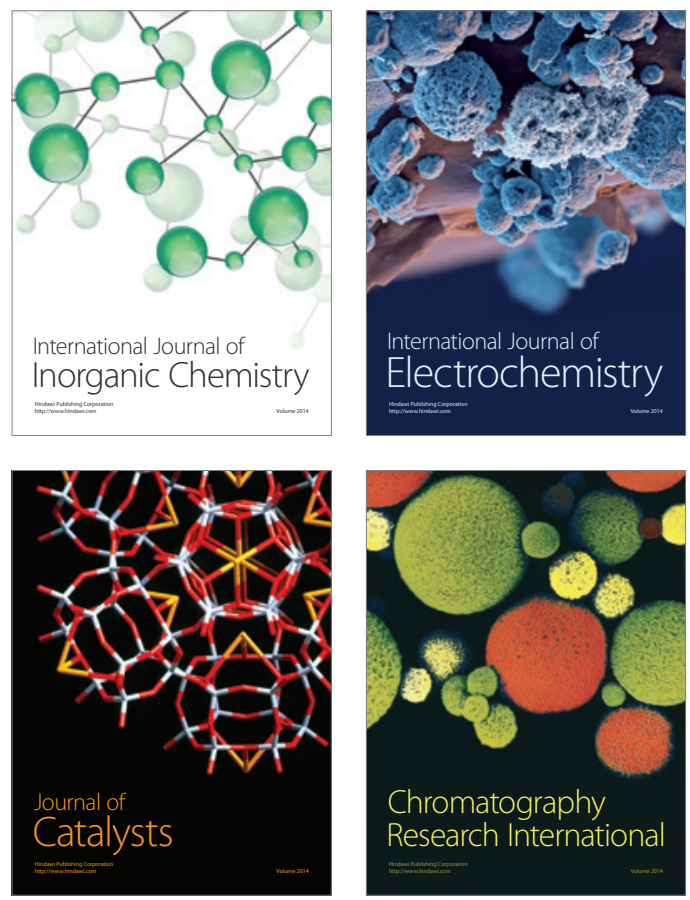
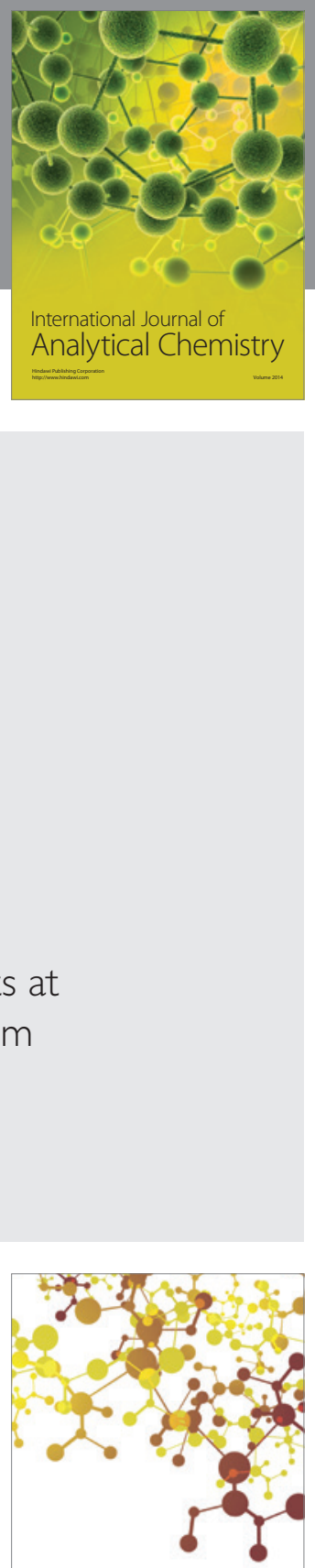

Journal of

Applied Chemistry
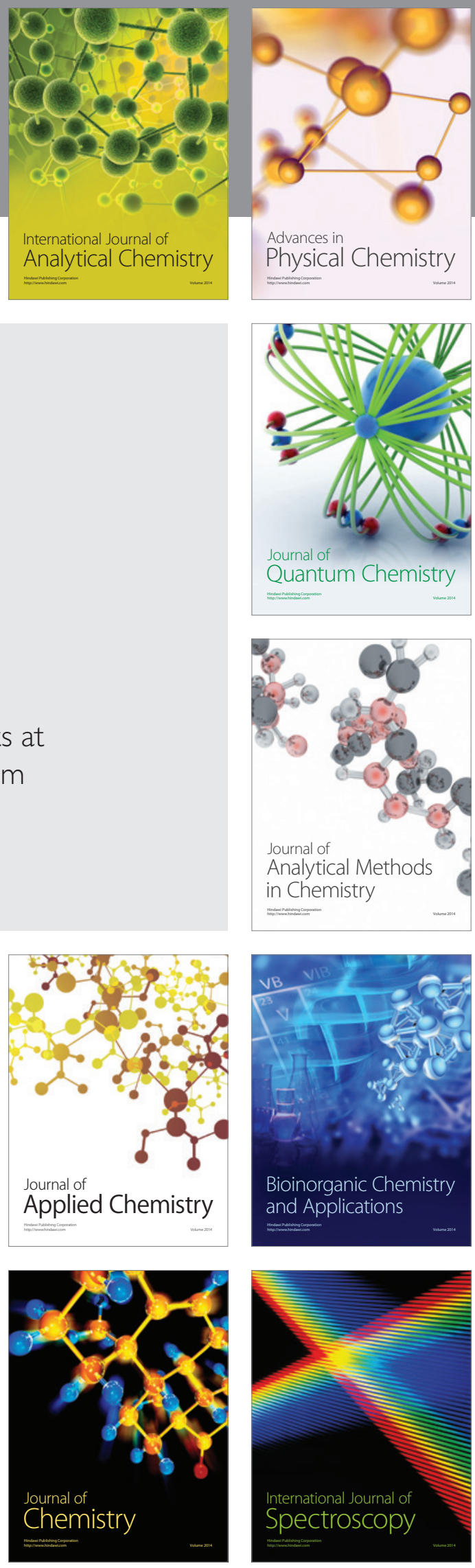